\title{
Unique challenges in pediatric anesthesia created by COVID-19
}

\author{
Nan Gai ${ }^{1} \cdot$ Jason T. Maynes ${ }^{1,2} \cdot$ Kazuyoshi Aoyama ${ }^{1,3}$ (1)
}

Received: 21 July 2020 / Accepted: 24 July 2020 / Published online: 7 August 2020

(c) Japanese Society of Anesthesiologists 2020

\begin{abstract}
Coronavirus disease 2019 (COVID-19) has affected anesthetic care worldwide, including the provision of anesthesia for pediatric patients. Hospitals have balanced the risks associated with the potential surges of resource-intensive COVID-19 patients against the probable morbidity of delaying elective surgical procedures. These decisions are complicated by the unclear influence that COVID-19 has on the perioperative risk for disease-positive pediatric patients. We conducted a comprehensive literature search on MEDLINE for publications involving pediatric patients with COVID-19 who underwent general anesthesia. A total of eight publications met inclusion criteria, and together described 20 patients. Nine patients had documented preoperative COVID-19 symptoms and one perioperative death was reported. Overall, further studies are needed to increase patient numbers and properly assess the perioperative risk. As we continue to provide care without clear guiding data, we present a discussion of modified anesthetic techniques for pediatric patients with suspected or confirmed COVID-19.
\end{abstract}

Keywords COVID-19 $\cdot$ SARS-CoV-2 $\cdot$ Transmission risk $\cdot$ Pediatric anesthesia $\cdot$ Perioperative outcomes

\section{Introduction}

In North America, most pediatric hospitals canceled or delayed elective surgeries at the onset of the coronavirus disease 2019 (COVID-19) pandemic in an effort to preserve health-care resources for an anticipated surge of high-needs COVID-19 patients, and to prevent the spread of the disease in hospitals [1]. This strategy kept hospital bed and intensive care unit occupancy below capacity, but at the cost of extending elective surgery wait times. Delays in elective surgeries become problematic when prolonged

Electronic supplementary material The online version of this article (https://doi.org/10.1007/s00540-020-02837-0) contains supplementary material, which is available to authorized users.

Kazuyoshi Aoyama

kazu.aoyama@utoronto.ca

1 Department of Anesthesia and Pain Medicine, The Hospital for Sick Children, 555 University Ave, \#2211, Toronto, ON M5G 1X8, Canada

2 Program in Molecular Medicine, SickKids Research Institute, 686 Bay St, Toronto, ON M5G 0A4, Canada

3 Program in Child Health Evaluative Sciences, SickKids Research Institute, 686 Bay St, Toronto, ON M5G 0A4, Canada extensions affect the efficacy of the surgical outcome, or when additional patient morbidity is incurred as a result of the delayed repair of the underlying condition. The latter may cause emergent patient admission to facilitate the awaited surgical procedure and to deal with the newly created complications. For instance, a wait time for surgery of more than 14 days from diagnosis was associated with a doubling of the risk of hernia incarceration among infants and young children with inguinal hernia [2]. The concerns for compromised patient outcomes from delayed procedures has prompted many jurisdictions to resume elective surgeries before the pandemic has ended, requiring a balance with the risks of viral transmission. The aim of this review is to highlight concerns unique to pediatric anesthesia practice in the context of COVID-19 and to develop solutions to these challenges with the best currently available evidence.

\section{Perioperative outcomes in children with COVID-19}

An international, multicentre, cohort study conducted during the early phase of the COVID-19 pandemic examined adults who were diagnosed with COVID-19 within a time period spanning seven preoperatively to 30 days postoperatively. Significantly, major perioperative outcomes included an astounding $23.8 \%$ mortality rate at postoperative day 30 
and a $51.2 \%$ incidence of pulmonary complications, including pneumonia and unexpected postoperative ventilation [3]. This singular manuscript provides some insight into the perioperative risks for adults with COVID-19, but no similar cohort data is available for outcomes in children. Thus, we conducted a comprehensive literature search through MEDLINE on July 7th, 2020, containing sets of terms reflecting our topic of interest including the disease (COVID-19, severe acute respiratory syndrome coronavirus 2 (SARS$\mathrm{CoV}-2)$ ), perioperative period, and pediatric patients, which yielded 152 abstracts (Supplementary online resource 1). Out of these abstracts, we identified 7 case reports/series [4-10] and 1 retrospective cohort study [11].

Table 1 summarizes a total of 20 pediatric patients with diagnosed COVID-19 who underwent general anesthesia. Out of 20 patients, 12 required emergent surgeries and 9 patients had preoperative symptoms such as cough, fever, rhinorrhea, or diarrhea. Three patients who required noninvasive ventilation postoperatively did not have any preoperative symptoms, and were subsequently diagnosed with COVID-19 [4, 7, 8]. One patient mortality occurred, as a result of small bowel necrosis secondary to intussusception, and concurrent acute respiratory failure due to COVID-19 pneumonia [6]. Although not insignificant, the rates and severity of negative perioperative outcomes in children are less than adults, but based on limited reported data. Further research is warranted to properly describe perioperative risks and outcomes in children diagnosed with COVID-19.

\section{Preoperative evaluation in children}

The transmission of SARS-CoV-2 is a significant concern for anesthesiologists and other personnel performing (or near) an aerosol generating procedure (AGP). An evaluation of SARS-CoV transmission during endotracheal intubation found a significant risk of viral transmission to health-care workers performing the procedure (Odds Ratio [95\% Confidence Intervals]: 6.6 [4.1-10.6]), and a lower but significant risk of transmission during bag-mask ventilation (Odds Ratio [95\% Confidence Intervals]: 2.8 [1.3-6.4]) [12]. The risk to pediatric care providers is increased by the higher level of asymptomatic carriers in the young (up to 50\%) [13] and the relative insensitivity of the most-widely utilized SARS-CoV2 testing methods (reverse transcriptase polymerase chain reaction, with a sensitivity of only $70 \%$ ) [14]. Additionally, there is evidence that asymptomatic carriers have very similar upper respiratory tract viral loads to symptomatic patients $[15,16]$, and that the virus may be shed in pediatric patient stool (although viral viability has not been established) [17].

When compared with those performing an AGP in adult patients, pediatric clinicians must then modify standard techniques to minimize the generation of aerosols and droplets, ensuring the use of personal protective equipment (PPE) [14] even in patients who fail to show signs of disease or who have a negative SARS-CoV-2 diagnostic test. In a retrospective analysis of 1295 patients presenting for surgery, less than one percent tested positive for SARS-CoV-2 ( 9 patients in total) [11]. Patients with COVID-19 had a higher incidence of preoperative symptoms ( $50 \%$ vs. $12.2 \%$ ), including a fourfold higher risk of fever and an eight-fold higher risk of cough, as compared to the patients that tested negative, providing predictive value. For the purposes of safety during AGPs, these findings also lower the importance of preoperative viral testing for pediatric patients, as similar precautions should be taken with or without a negative test. They do not negate the importance of identifying COVID-19 positive patients for the purposes of peri-operative isolation, as a potential contributor to postoperative outcomes, or for contract tracing.

A multisystem inflammatory syndrome (MIS) has been described in children, temporally associated with SARSCoV-2 infection, although the causative link has not been established [18, 19]. Patients with MIS, described as similar to Kawasaki Disease with systemic inflammation and potentially coronary artery aneurysms, have an astoundingly high incidence of myocardial dysfunction (38-50\%) and a need for inotropic support and fluid resuscitation (48-79\%). The induction of anesthesia can induce significant hemodynamic instability, especially in patients with underlying cardiac dysfunction. Consideration for the presence of MIS should be taken before the start of anesthesia, as this may modify the induction technique or drug choice.

\section{The induction of general anesthesia in children}

Parental presence at induction is routinely used as a method to reduce the anxiety at the induction of anesthesia in children; however, the practise increases the use of PPE supply and potentially increases health-care provider virus exposure from the caregiver [20]. Sedative premedication is recommended to minimize anxiety and the risk of crying with subsequent aerosol generation. If no intravenous route for sedation is available, other routes of administration (oral or intranasal) may require a careful assessment of risks and benefits. Intranasal administration has been cautioned against because of concerns for induced coughing, although this complication is relatively rare [21]. It is important to highlight that bitter-tasting oral solutions containing midazolam will also induce responses such as spitting, coughing, and crying [22].

A unique consideration for pediatric anesthesia is the usual practise of performing inhalational inductions in patients presenting without intravenous access. Although an intravenous technique may be preferred to minimize aerosol generation during induction [20], especially in children 
Journal of Anesthesia (2021) 35:345-350

347

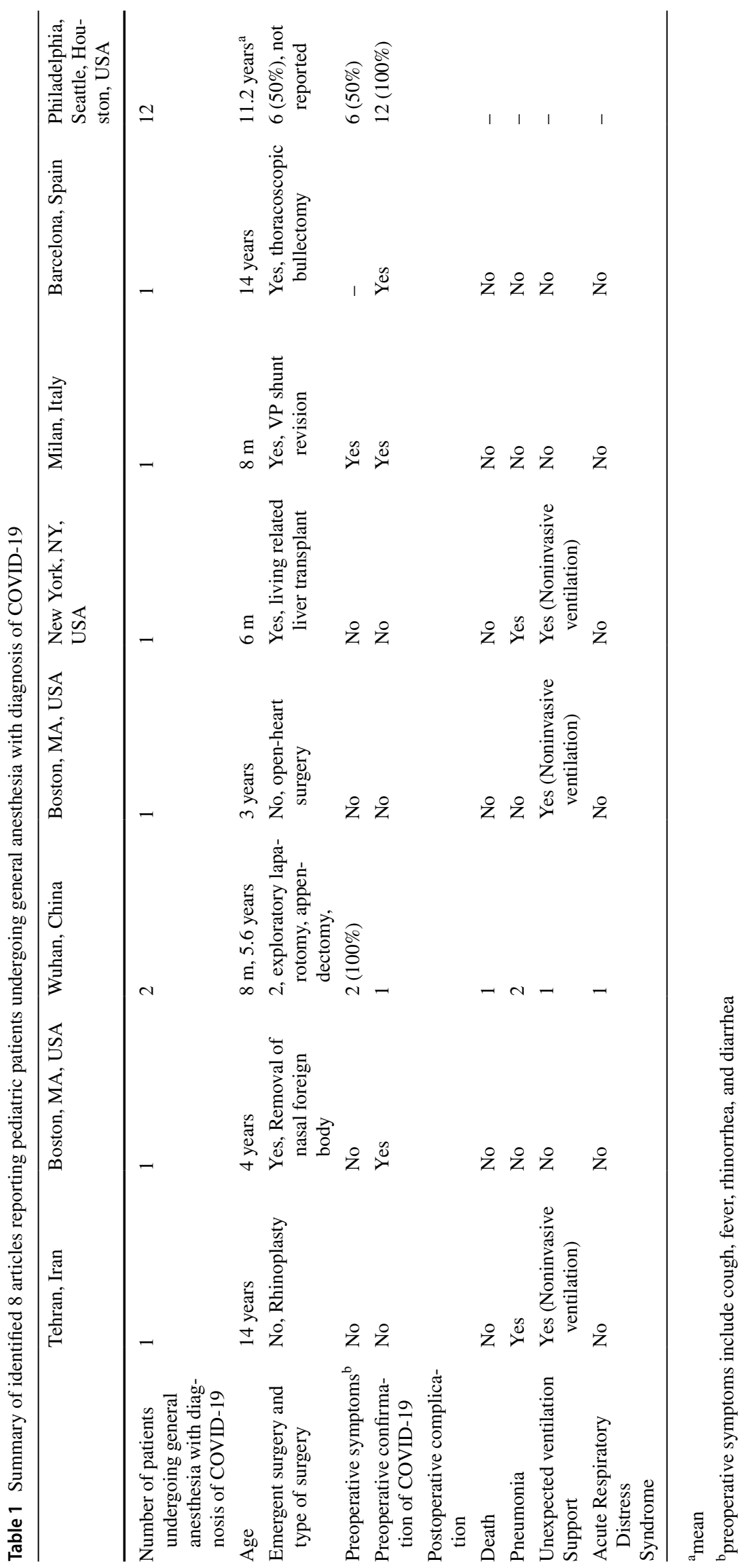

Springer 
Table 2 Considerations for modification of anesthetic technique in pediatric patients with suspected or confirmed COVID-19

\begin{tabular}{|c|c|c|}
\hline & Prevent aerosol and droplet generation & Minimize exposure \\
\hline Preoperative & $\begin{array}{l}\text { Minimize crying-premedication, nonpharmacologic anxiolysis (distrac- } \\
\text { tion techniques, videos, games), topical anesthetic for IV insertion }\end{array}$ & $\begin{array}{l}\text { Discuss delaying procedure until acute infection has } \\
\text { resolved (if possible) } \\
\text { Appropriate donning of Personal Protective Equip- } \\
\text { ment }\end{array}$ \\
\hline Induction & $\begin{array}{l}\text { IV induction-Consider Rapid Sequence Induction (RSI), avoid or mini- } \\
\text { mize Bag Mask Ventilation } \\
\text { Inhalational induction-Tight seal, avoid high flows }\end{array}$ & $\begin{array}{l}\text { Avoid Parental Presence at Induction } \\
\text { Minimal staff present }\end{array}$ \\
\hline Extubation & $\begin{array}{l}\text { Prevent coughing-deep extubation, adjuncts (dexmedetomidine, lido- } \\
\text { caine, opioids) }\end{array}$ & Minimal staff present \\
\hline Postoperative & Recover in Negative Pressure Isolation Room or in the Operating Room & $\begin{array}{l}\text { Minimize transport throughout hospital } \\
\text { Appropriate doffing of Personal Protective Equipment }\end{array}$ \\
\hline
\end{tabular}

with a high risk for perioperative respiratory events [23], the process of securing intravenous access preoperatively in children could itself cause crying and generate aerosols and droplets. However, the excitation phase of inhalational induction can also induce coughing or breath holding, necessitating bag mask ventilation, which itself generates further aerosols. The decision of the method of induction will therefore be patient- and anesthesiologist-dependent after a balance of the risks and benefits in each specific situation [24]. When proceeding with an inhalational induction, there is suggestion that the induction time can be shortened using a higher initial concentration of sevoflurane, with no significant increase in undesirable effects such as cough, laryngospasm, or breath holding [25]. A tight seal with the facemask and avoiding high gas flows may be beneficial to minimize any exposure to personnel in the room.

For an intravenous induction of anesthesia, a rapid sequence technique can help avoid bag-mask ventilation and coughing [26]. Techniques such as video laryngoscopy have been recommended to place the intubator's face further away from the patient, however this must be balanced with the comfort level of the anesthesiologist with different laryngoscopy techniques in children and the relative speed and first-pass success rate of securing the airway. "Intubation box" or "aerosol box" was proposed to protect an intubator against exposure to a spread of droplets and aerosols generated from the coughing of a patient during endotracheal intubation [27]. The box works by covering a patient's head with a transplacental plastic cube, and an intubator can operate the airway procedure through two circular ports. The safe use of such a box, however, is not established yet [28].

Table 2 summarizes in considerations for modification of anesthetic technique in pediatric patients with suspected or confirmed COVID-19. Consensus guidelines have been published for airway management in pediatric patients with suspected or confirmed COVID-19 [20].

\section{Emergence and extubation in pediatric anesthesia in the COVID-19 era}

Equal consideration should be given to patient extubation to minimize the droplet and aerosol generation, with a comparable or higher risk of respiratory complications as compared to intubation [29]. Although it is unclear whether there is a benefit to deep extubation of patients, it has been predicted as protective for aerosol generation [20]. One meta-analysis has shown that deep extubation in pediatric patients may be protective against coughing and desaturation but may lead to increased airway obstruction [30], and second study showed that deep extubation was associated with an increased risk of severe respiratory critical events [31]. Adjunctive medications to minimize coughing after extubation can also be considered, including dexmedetomidine, remifentanil, fentanyl, or lidocaine [32]. Although nonspecific, patients with severe COVID-19 have substantially higher inflammatory markers (CRP, procalcitonin), as compared to those with mild disease, which may provide predictive value for postoperative complications [33].

Ideally, patients with confirmed COVID-19 should be recovered in a negative pressure recovery room [34]. If unavailable, then recovery within the operating room should occur, with the additional benefit of minimizing transport and exposure to other areas of the hospital. Many advisories have recommended the prolonged wearing of N95 masks for conservation of PPE supplies [35]. For cases of confirmed or high suspicion COVID-19, however, all PPE, including N95 masks, 
should be doffed completely to minimize further exposure risk. Cleaning of the operating rooms afterwards should be thorough, with the approach of an "enhanced terminal cleaning" [36].

\section{Conclusion}

The provision of anesthesia for the pediatric population during COVID-19 possesses unique challenges. Although the documented incidence of disease is lower in children, the high asymptomatic carrier rate increases the risk of viral transmission to other patients and care providers. A lower disease incidence puts greater emphasis on an integrated and real-time translation of knowledge and experience to ensure the ongoing safe provision of necessary patient care during an uncertain period [37]. Anesthesiologists should continue to adopt their expertise to each pediatric patient, according to the patient's individual characteristics and the environment of their anesthesia practice, until enough evidence emerges to advocate for specific initiatives in the optimal perioperative care for children during COVID-19.

Acknowledgement Ms. Marina Englesakis, MLIS for her support of literature search.

Contribution to Authorship KA conceived this paper and had a systematic literature search. The first draft of the manuscript was written by NG, JTM and KA, and all authors critically revised the manuscript. All authors read and approved the final manuscript.

\section{Compliance with ethical standards}

Disclosures and declarations The authors declare that they have no conflict of interests related to this publication.

\section{References}

1. Livingston EH. Surgery in a time of uncertainty: a need for universal respiratory precautions in the operating room. JAMA J Am Med Assoc. 2020;323:2254-5.

2. Zamakhshary M, To T, Guan J, Langer JC. Risk of incarceration of inguinal hernia among infants and young children awaiting elective surgery. Can Med Assoc J. 2008;179:1001-5.

3. Archer JE, Odeh A, Ereidge S, Salem HK, Jones GP, Gardner A, et al. Mortality and pulmonary complications in patients undergoing surgery with perioperative SARS-CoV-2 infection: an international cohort study. Lancet. 2020;396:27-38.

4. Rahmanzade R, Rahmanzadeh R, Hashemian SMR. Respiratory Distress in Postanesthesia Care Unit: first presentation of coronavirus disease 2019 in a 17 -year-old girl: a case report. A\&A Pract. 2020;14:e01227.

5. Diercks GR, Park BJ, Myers LB, Kwolek CJ. Asymptomatic COVID-19 infection in a child with nasal foreign body. Int J Pediatr Otorhinolaryngol. 2020;135:110092.

6. Cai X, Ma Y, Li S, Chen Y, Rong Z, Li W. Clinical characteristics of 5 COVID-19 cases with non-respiratory symptoms as the first manifestation in children. Front Pediatr. 2020;8:1-9.
7. Shaw R, Tighe N, Odegard KC, Alexander P, Emani S, Yuki K. Intubation precautions in a pediatric patient with severe COVID-19. J Pediatr Surg Case Reports. 2020;58:101495.

8. Heinz N, Griesemer A, Kinney J, Vittorio J, Lagana SM, Goldner D, et al. A case of an Infant with SARS-CoV-2 hepatitis early after liver transplantation. Pediatr Transplant. 2020. https://doi.org/10.1111/ petr.13778.

9. Carrabba G, Tariciotti L, Guez S, Calderini E, Locatelli M. Neurosurgery in an infant with COVID-19. Lancet. 2020;395:e76.

10. Giné C, Laín A, García L, López M. Thoracoscopic bullectomy for persistent air leak in a 14-year-old child with COVID-19 bilateral pulmonary disease. J Laparoendosc Adv Surg Tech. 2020. https:// doi.org/10.1089/lap.2020.0289.

11. Lin EE, Blumberg TJ, Adler AC, Fazal FZ, Talwar D, Ellingsen K, et al. Incidence of COVID-19 in Pediatric Surgical Patients among 3 US Children's Hospitals. JAMA Surg. 2020;344:8-10.

12. Tran K, Cimon K, Severn M, Pessoa-Silva CL, Conly J. Aerosol generating procedures and risk of transmission of acute respiratory infections to healthcare workers: a systematic review. PLoS ONE. 2012;7:e35797.

13. Bialek S, Gierke R, Hughes M, McNamara LA, Pilishvili T, Skoff T. Coronavirus disease 2019 in children-United States, February 12-April 2, 2020. Morb Mortal Wkly Rep. 2020;69:422-6.

14. Cheng MP, Papenburg J, Desjardins M, Kanjilal S, Quach C, Libman M, et al. Diagnostic testing for severe acute respiratory syndrome-related coronavirus 2. Ann Intern Med. 2020;172:726-34.

15. Zou L, Ruan F, Huang M, Liang L, Huang H, Hong Z, et al. SARS$\mathrm{CoV}-2$ viral load in upper respiratory specimens of infected patients. N Engl J Med. 2020;382:1177-9.

16. Rothe C, Schunk M, Sothmann P, Bretzel G, Froeschl G, Wallrauch C, et al. Transmission of 2019-nCoV infection from an asymptomatic contact in Germany. N Engl J Med. 2020;382:970-1.

17. Xu Y, Li X, Zhu B, Liang H, Fang C, Gong Y, et al. Characteristics of pediatric SARS-CoV-2 infection and potential evidence for persistent fecal viral shedding. Nat Med. 2020;26:502-5.

18. Whittaker E, Bamford A, Kenny J, Kaforou M, Jones CE, Shah P, et al. Clinical characteristics of 58 children with a pediatric inflammatory multisystem syndrome temporally associated with SARSCoV-2. JAMA. 2020. https://doi.org/10.1001/jama.2020.10369.

19. Feldstein LR, Rose EB, Horwitz SM, Collins JP, Newhams MM, Son MBF, et al. Multisystem inflammatory syndrome in U.S. children and adolescents. N Engl J Med. 2020;383:334-46.

20. Matava CT, Kovatsis PG, Lee JK, Castro P, Denning S, Yu J, et al. Pediatric Airway Management in COVID-19 Patients: Consensus Guidelines From the Society for Pediatric Anesthesia's Pediatric Difficult Intubation Collaborative and the Canadian Pediatric Anesthesia Society. Anesth Analg. 2020;131:61-73.

21. Gilchrist F, Cairns AM, Leitch JA. The use of intranasal midazolam in the treatment of paediatric dental patients. Anaesthesia. 2007;62:1262-5.

22. Isik B, Baygin Ö, Bodur H. Effect of drinks that are added as flavoring in oral midazolam premedication on sedation success. Pediatr Anesth. 2008;18:494-500.

23. Ramgolam A, Hall GL, Zhang G, Hegarty M, von Ungern-Sternberg BS. Inhalational versus intravenous induction of anesthesia in children with a high risk of perioperative respiratory adverse events. Anesthesiology. 2018;128:1065-74.

24. Zielinska M, Holtby H, Wolf A. Pro-con debate: intravenous vs inhalation induction of anesthesia in children. Paediatr Anaesth. 2011;21:159-68.

25. Boonmak P, Boonmak S, Pattanittum P. High initial concentration versus low initial concentration sevoflurane for inhalational induction of anaesthesia. Cochrane Database Syst Rev. 2016;2016.

26. Soneru CN, Nunez K, Petersen TR, Lock R. Anesthetic concerns for pediatric patients in the era of COVID-19. Paediatr Anaesth. 2020. https://doi.org/10.1111/pan.13924. 
27. Canelli R, Connor CW, Gonzalez M, Nozari A, Ortega R. Barrier enclosure during endotracheal intubation. $\mathrm{N}$ Engl J Med. 2020;382:1957-8.

28. Begley JL, Lavery KE, Nickson CP, Brewster DJ. The aerosol box for intubation in coronavirus disease 2019 patients: an in situ simulation crossover study. Anaesthesia. 2020;75:1014-21.

29. Asai T, Koga K, Vaughan RS. Respiratory complications associated with tracheal intubation and extubation. Br J Anaesth. 1998;80:767-75.

30. Koo C-H, Lee S, Chung S, Ryu J-H. Deep vs. awake extubation and LMA removal in terms of airway complications in pediatric patients undergoing anesthesia: a systemic review and meta-analysis. J Clin Med. 2018;7:353.

31. Habre W, Disma N, Virag K, Becke K, Hansen TG, Jöhr M, et al. Incidence of severe critical events in paediatric anaesthesia (APRICOT): a prospective multicentre observational study in 261 hospitals in Europe. Lancet Respir Med. 2017;5:412-25.

32. Tung A, Fergusson NA, Ng N, Hu V, Dormuth C, Griesdale DEG. Medications to reduce emergence coughing after general anaesthesia with tracheal intubation: a systematic review and network metaanalysis. Br J Anaesth. Elsevier Ltd. 2020;124:480-95.
33. Zachariah P, Johnson CL, Halabi KC, Ahn D, Sen AI, Fischer A, et al. Epidemiology, clinical features, and disease severity in patients with coronavirus disease 2019 (COVID-19) in a Children's Hospital in New York City, New York. JAMA Pediatr. 2020;e202430.

34. Lee-Archer P, von Ungern-Sternberg BS. Pediatric anesthetic implications of COVID-19-a review of current literature. Paediatr Anaesth. 2020. https://doi.org/10.1111/pan.13889.

35. Kobayashi LM, Marins BR, Costa PC dos S, Perazzo H, Castro R. Extended use or reuse of N95 respirators during COVID-19 pandemic: an overview of national regulatory authority recommendations. Infect Control Hosp Epidemiol. 2020;1-3.

36. Dexter F, Parra MC, Brown JR, Loftus RW. Perioperative COVID19 defense: an evidence-based approach for optimization of infection control and operating room management. Anesth Analg. 2020;131:37-42.

37. Angus DC. Optimizing the Trade-off between Learning and Doing in a Pandemic. JAMA J Am Med Assoc. 2020;323:1895-6.

Publisher's Note Springer Nature remains neutral with regard to jurisdictional claims in published maps and institutional affiliations. 